\title{
COMPETÊNCIAS GERAIS DA BASE NACIONAL COMUM CURRICULAR (BNCC): FUNDAMENTOS TEÓRICOS E IDEOLÓGICOS
}

\author{
GENERAL COMPETENCIES OF THE NATIONAL COMMON CURRICULAR BASE \\ (BNCC): THEORETICAL AND IDEOLOGICAL FOUNDATIONS
}

\author{
Amanda Melchiotti Gonçalves \\ Doutoranda em Educação pela Universidade do Oeste do Paraná \\ UNIOESTE - Campus de Cascavel - PR. Pesquisadora do Grupo de estudos e pesquisas em Política \\ Educacional e Social - GEPPES \\ amandamelchiottigoncalves@gmail.com
}

Roberto Antonio Deitos

Doutor em Educação pela Universidade Estadual de Campinas - UNICAMP. Pós-Doutor em Educação pela Universidade Estadual de Maringá - UEM. Professor Associado da Universidade Estadual do Oeste do Paraná UNIOESTE - Campus de Cascavel - PR, Centro de Educação, Comunicação e Artes, Colegiado do Curso de Pedagogia. Pesquisador do Grupo de Estudos e Pesquisas em Política Educacional e Social - GEPPES rdeitos@uol.com.br

\begin{abstract}
Resumo: Este artigo objetiva analisar os fundamentos teóricos e ideológicos das Competências Gerais da Base Nacional Comum Curricular (BNCC). Para tanto, dispõe-se dos seguintes documentos: a própria BNCC, o documento divulgado pelo Movimento pela Base Nacional Comum Curricular e o documento Educação em Quatro Dimensões, divulgado pelo Center for Curriculum Redesign. A partir dessa análise, percebe-se que o discurso neoliberal das reformas educacionais, empreendidas ainda na década de 1990, continua presente nas propostas curriculares e são observáveis na reforma proposta pela BNCC, por meio das dez Competências Gerais. Os argumentos são de que a educação pautada em competências representa a noção ideológica de um pensamento que visa moldar os indivíduos às exigências socioeconômicas. A fim de "ajustar" o ser humano ao seu ambiente e à sua cultura, as Competências Gerais da BNCC expressam teórica e ideologicamente os valores essenciais para o século XXI. Logo, essas competências, tais como consignadas nesse documento, refletem a conservação e reprodução de uma sociedade desigual, pautada nos interesses das classes dominantes.
\end{abstract}

Palavras-chave: Estado. Educação. Competências Gerais da BNCC.

\begin{abstract}
This article aims to analyze the theoretical and ideological foundations of the General Competencies of the National Common Curricular Base (BNCC). For this purpose, the following documents are available: the BNCC itself, the document released by the Movement by the Common Base National Curriculum and the document Education in Four Dimensions, released by the Center for Curriculum Redesign. From this analysis, it is clear that the neoliberal discourse of educational reforms, undertaken in the 1990s, is still present in the curricular proposals and is observable in the reform proposed by the BNCC, through the ten General Competencies. The arguments are that education based on competences represents the ideological notion of a thought that aims to mold individuals to socioeconomic requirements. In order to 'adjust' human beings to their environment and culture, the General Competencies of the BNCC express theoretically and ideologically the essential values for the 21 st century. Therefore, these competences, as stated in this document, reflected in the conservation and reproduction of an unequal society, based on the interests of the dominant classes.
\end{abstract}

Keywords: State. Education. General Competencies of BNCC.

\section{Para citar - (ABNT NBR 6023:2018)}

GONÇALVES, Amanda Melchiotti; DEITOS, Roberto Antonio. Competências gerais da Base Nacional Comum Curricular (BNCC): fundamentos teóricos e ideológicos. Eccos - Revista Cientifica, São Paulo, n. 52, p. 1-19, e10678, jan./mar. 2020. Disponível em: https://doi.org/10.5585/eccos.n52.10678. 


\section{Introdução}

Este artigo tem como objetivo analisar os fundamentos teóricos e ideológicos das Competências Gerais da Base Nacional Comum Curricular (BNCC). Para tanto, dispõe-se dos seguintes documentos: Base Nacional Comum Curricular (BNCC) ${ }^{1}$, que apresenta dez Competências Gerais; Dimensões e Desenvolvimento das Competências Gerais da BNCC, divulgado pelo Movimento pela Base Nacional Comum Curricular; e Educação em Quatro Dimensões: As competências que os estudantes precisam ter para atingir o sucesso, do Center for Curriculum Redesign (CCR).

Esta análise está baseada no entendimento de que as políticas educacionais representam a materialização do Estado como parte das relações sócio-históricas (PERONI, 2011). Nesse sentido, parte-se do pressuposto de que há uma influência crescente dos organismos internacionais que transparece na elaboração das políticas internas dos países (CARVALHO, 2010), as quais submetem as políticas educacionais aos imperativos da economia global de forma a constituir uma agenda globalmente estruturada para a educação. (DALE, 2004)

A fim de dar ênfase ao objetivo proposto, utilizar-se-á o documento Educação em Quatro Dimensões, divulgado em 2015 pelo Center for Curriculum Redesign ${ }^{2}$, com a finalidade de evidenciar sua relação de influência com os fundamentos teóricos e ideológicos das Competências Gerais da BNCC, uma vez que as políticas educacionais contemporâneas “[...] articulam interesses, projetam políticas, produzem intervenções sociais.” (EVANGELISTA, 2012, p. 52).

Assim, a partir de uma análise de cunho qualitativo, bibliográfico e documental, buscase responder, neste artigo, a seguinte questão: Quais os fundamentos teóricos e ideológicos das Competências Gerais da BNCC? Para responder a esse questionamento, o artigo divide-se em duas seções: a primeira busca compreender a configuração do Estado partindo dos fundamentos ideológicos, socioeconômicos e políticos; a segunda evidencia a relação das competências com as organizações internacionais, especialmente o CCR, e, por fim, tecem-se as considerações finais do trabalho.

\section{Estado e educação: fundamentos ideológicos, socioeconômicos e políticos}

O Estado é a materialização das relações sócio-históricas (PERONI, 2011), bem como o condicionante indispensável para a formação e consolidação das estruturas reprodutivas que mantêm o funcionamento ininterrupto do modo de produção capitalista (MÉSZÁROS, 2002). 
Assim, o capitalismo repõe sua dinâmica reprodutiva em razão dos poderosos fatores ideológicos de manutenção da ordem social existente (MÉSZÁROS, 2012). Essa compreensão acerca do ente estatal baseia-se na concepção de Marx e Engels (1998), cujo entendimento é de que os pensamentos da classe dominante são os pensamentos dominantes. Nessa perspectiva de análise, depreende-se que à classe proprietária dos meios de produção é facultado o exercício do pensamento dominante como a forma de expressão ideal das relações materiais dominantes. Nas palavras de Marx e Engels (1998), o Estado é a forma em que os indivíduos da classe dominante fazem valer seus interesses comuns e

[...] na qual se resume toda a sociedade civil de uma época, conclui-se que todas as instituições públicas têm o Estado como mediador e adquirem através dele uma forma política. Daí a ilusão de que a lei repousa sobre a vontade e, melhor ainda, sobre uma vontade livre, desligada da base concreta. (MARX; ENGELS, 1998, p. 74).

A igualdade perante a lei, isto é, a igualdade ante o direito é uma ilusão, uma vez que as relações de força e poder entre capital e trabalho são estruturalmente desiguais - por isso a ideologia burguesa opera eficazmente a favor de seus interesses (FRIGOTTO, 2010). Posto isso, é possível compreender que "[...] a ideologia dominante tem interesse em preservar o status quo, em que até as desigualdades mais patentes já estão estruturalmente entrincheiradas e garantidas" (MÉSZÁROS, 2012, p. 327), ou seja, a 'unidade orgânica' do pensamento ideológico da cultura liberal-conservadora está estruturalmente hierarquizada pela dominação e subordinação, de modo que a ordem socioeconômica estabelecida deve constantemente se ajustar às condições de dominação. (MÉSZÁROS, 2012).

A estrutura social reprodutiva do capitalismo se altera ao longo da história. Exemplo disso é a reestruturação produtiva do século XX, caracterizada por mudanças no sistema produtivo que alteraram também as formas modelares do trabalho. Para Batista (2017), de meados da década de 1940 até meados de 1960 o sistema do capital conviveu com duas décadas de expansão devido às excepcionais taxas de crescimento vividas no contexto do pós-Segunda Guerra Mundial, denominado por Hobsbawm (2017) como 'Era de Ouro' do capitalismo, período representado pelo modelo taylorista-fordista de produção. No entanto, corrida a década de 1960, o capital passou a enfrentar os primeiros sintomas de crise, que se revelou uma crise estrutural e de longa duração (BATISTA, 2017). A partir da década de 1970 e se estendendo aos anos de 1980, a crise de reprodução do capital encontrou sobrevida na implantação de novas formas de reestruturação do modelo produtivo industrial, que ficou conhecido como toyotismo, caracterizando um período, ainda atual, de acumulação flexível conforme definida por Harvey (1999, p. 140): 


\begin{abstract}
A acumulação flexível, como vou chamá-la, é marcada por um confronto direto com a rigidez do fordismo. Ela se apoia na flexibilidade dos processos de trabalho, dos mercados de trabalho, dos produtos e padrões de consumo. Caracteriza-se pelo surgimento de setores de produção inteiramente novos, novas maneiras de fornecimento de serviços financeiros, novos mercados e, sobretudo, taxas altamente intensificadas de inovação comercial, tecnológica e organizacional. (HARVEY, 1999, p. 140).
\end{abstract}

No contexto da globalização, tal processo de acumulação passa a exigir da educação a formação de capital humano voltado a produzir um trabalhador flexível e com uma nova qualificação humana (FRIGOTTO, 2010). Para Shiroma, Moraes e Evangelista (2011), a literatura internacional retomou a teoria do capital humano, muito evidente nos anos de 1970, que afirmava ser a educação a principal determinante da competitividade entre os países, ou seja, alegava-se que o paradigma produtivo demandava os requisitos da educação geral e da qualificação profissional dos trabalhadores.

Parte-se, assim, do pressuposto de que há uma influência crescente dos organismos internacionais que transparece na elaboração das políticas internas dos países (CARVALHO, 2010), as quais submetem as políticas educacionais aos imperativos da economia global de forma a constituir uma Agenda Globalmente Estruturada para a Educação, vista como " [...] a mudança de natureza da economia capitalista mundial como a força directora da globalização e procura estabelecer os seus efeitos, ainda que intensamente mediados pelo local, sobre os sistemas educativos." (DALE, 2004, p. 426) Por força da constituição de uma economia global, essa agenda educativa global passa a fazer parte da nova ordem econômica mundial na medida em que são difundidas por organismos internacionais, tais como: Fundo Monetário Internacional (FMI), Banco Interamericano de Desenvolvimento (BID), Banco Internacional para Reconstrução e Desenvolvimento (BIRD), Organização das Nações Unidas para a Educação, a Ciência e a Cultura (UNESCO), Organização Internacional do Trabalho (OIT), Fundo das Nações Unidas para a Infância (UNICEF), Agência dos Estados Unidos para o Desenvolvimento Internacional (USAID), Centro Interamericano de Desenvolvimento do Conhecimento em Formação Profissional (CEPAL/CINTERFOR), Escritório Regional de Educação para a América Latina e o Caribe (OREALC) e Organização Mundial do Comércio (OMC). Esses organismos, por sua vez, pautam seu receituário na teoria do capital humano e, assim, políticas, sistemas e processos educativos escolares nacionais ao imediatismo da formação técnico-profissional restrita. (FRIGOTTO, 2010)

A concepção de formação baseada na teoria do capital humano sempre esteve pautada no discurso do avanço tecnológico. É assim que, frente ao processo de reestruturação produtiva, popularizaram-se os conceitos de lean production e just-in-time, e "Disseminou-se a ideia de 
que para 'sobreviver' à concorrência do mercado, para conseguir ou manter um emprego, para ser cidadão do século XXI, seria preciso dominar os códigos da modernidade." (SHIROMA, MORAES, EVANGELISTA, 2010, p. 47 - grifo do nosso).

A partir de 1980, intensifica-se alguns conceitos e categorias pautados na acumulação flexível, que por consequência, desencadeou um novo modelo organizacional para a educação baseado na sociedade do conhecimento. Sobre isso, Frigotto (2010) ressalta:

\begin{abstract}
No plano da ordem econômica, os conceitos ou categorias pontes são: flexibilidade, participação, trabalho em equipe, competência, competitividade e qualidade total. No plano da formação humana são: pedagogia da qualidade, multi-habilitação, policognição polivalência e formação abstrata. Nesta perspectiva configura-se uma crescente unanimidade do discurso da 'modernidade' em defesa da escola básica de qualidade. (FRIGOTTO, 2010, p. 59).
\end{abstract}

Essas são as características da educação no plano da flexibilidade produtiva global, que tem sua base teórico-política pautada no neoliberalismo, cuja influência mais evidente, no Brasil, se dá a partir da década de 1990. Nesse sentido, Perrude (2017) analisa que, sob os princípios do neoliberalismo e baseada nas exigências do mercado, a educação foi pensada numa perspectiva racional, pois está articulada “aos princípios econômicos da competitividade, da flexibilidade e dos resultados, com o objetivo de elevar o nível de produtividade das populações a serviço de interesse privados diversos." (PERRUDE, 2017, p. 49) O neoliberalismo se constitui, portanto, num conjunto de políticas pautado num programa de reformas que visa submeter as instâncias da vida social à lógica de mercado (NOMA, 2017). É por isso que Shiroma, Moraes e Evangelista (2011) denunciam o discurso que atribui à educação a expectativa salvacionista de sustentação da competitividade dos anos de 1990, a qual, suportada em

[...] vasta documentação internacional, emanada de importantes organismos multilaterais, propalou esse ideário mediante diagnósticos, análises e propostas de soluções considerados cabíveis a todos os países da América Latina e Caribe, no que toca tanto à educação quanto à economia. (SHIROMA; MORAES; EVANGELISTA, 2011, p. 47).

Essa referida documentação faz parte da Agenda Globalmente Estruturada para a Educação referida por Dale (2004), na medida em que foi assumida e difundida pelos organismos internacionais como recomendação aos sistemas educativos. No Brasil, o receituário neoliberal se torna evidente a partir da década de 1990, haja vista que as relações sociais de produção e a presença determinante do capital nas propostas de políticas educacionais do Estado passaram a ter impacto na organização da escola, principalmente no currículo. Constatam-se essas recomendações no texto dos Parâmetros Curriculares Nacionais (PCN) e 
das Diretrizes Curriculares Nacionais para o Ensino Fundamental. Essas novas definições curriculares foram balizadoras de outras políticas, como a do livro didático e das avaliações, que passaram a se estruturar em larga escala.

Para Deitos (2008), o Brasil dos anos de 1990 foi marcado por um processo de consolidação da globalização sustentado politicamente pelo neoliberalismo. A principal mudança desse período foi a reforma do aparelho de Estado, de 1995, que definiu objetivos de reorganização da administração pública brasileira voltados à modernização gerencial, como se vê no documento do Ministério da Reforma do Estado:

É preciso, agora, dar um salto adiante, no sentido de uma administração pública que
chamaria de "gerencial", baseada em conceitos atuais da administração e eficiência,
voltada para o controle dos resultado e descentralizada para poder chegar ao cidadão,
que, numa sociedade democrática, é quem dá legitimidade às instituições e que,
portanto, se torna "cliente privilegiado" dos serviços prestados pelo Estado. (BRASIL,
1995, p. 10).

Reformar o Estado era essencial para atender aos novos requisitos de um mundo globalizado. Nessa conjuntura, prevaleceu o redirecionamento para novos modelos de gestão, preponderando a descentralização e flexibilização da estrutura organizacional da administração pública. O novo modelo de organização e os princípios da reforma demarcaram as novas perspectivas de organização na educação. Assim, “descentralização, privatização, novas formas de gestão, controle local e comunitário das escolas são propostas com grande eco no setor educacional.” (PAIVA; WARDE, 1993, p. 19).

Para Perrude (2017), as novas exigências administrativas se materializaram também nos vários planos educacionais: Plano Decenal de Educação (PDE), Plano Nacional de Educação (PNE) e o Plano de Desenvolvimento Educacional (PDE). Para a autora, esses planos têm o propósito de dar legitimidade às reformas empreendidas ao longo da década. Diversos foram os programas educacionais lançados desde a gestão de Fernando Henrique Cardoso (FHC) até a gestão de Inácio Lula da Silva (Lula) e Dilma. Logo, compreende-se que do ponto de vista estrutural os dois governos mantiveram o mesmo modelo econômico, bem como a mesma política social.

Atualmente, uma nova reforma curricular vem sendo implantada no Brasil com a Base Nacional Comum Curricular (BNCC), documento que reúne objetivos de aprendizagem em quatro áreas do conhecimento: Linguagens, Matemática, Ciências e Ciências Humanas, além de determinar o conjunto de conhecimentos e habilidades considerados necessários para todos os brasileiros em cada ano de ensino na escola básica e define dez Competências Gerais pertinentes ao desenvolvimento do aluno no decorrer de sua trajetória escolar na Educação 
Básica (Educação Infantil, Ensino Fundamental e Ensino Médio). Sem o intuito de trabalhá-las isoladamente, a reflexão que se pretende fazer na próxima seção busca analisar as relações entre os fundamentos teórico-ideológicos dessas competências, conforme consignadas nas recomendações das organizações internacionais sintetizadas nas propostas do Center For Curriculum Redesign.

\section{Competências Gerais da BNCC e as organizações internacionais}

No Brasil, na década de 1990, consolidou-se o processo de globalização num contexto em que sociedade, economia e Estado foram imbricados aos interesses internos e externos das classes hegemônicas nacionais, que intensificaram a alternativa neoliberal por meio da internacionalização da economia e da consolidação da reforma do Estado brasileiro. (DEITOS, 2008). A condição de uma economia, uma sociedade e um Estado nacional marcados pelos interesses internos e externos, firmou-se, principalmente no período da globalização, no chamado Consenso de Washington, documento que resultou de reunião de instituições multilaterais, em 1989, na capital dos Estados Unidos, cujo objetivo foi discutir reformas que se diziam 'necessárias' aos países da América Latina:

O objetivo do encontro, convocado pelo Institute for International Economics, sob o título "Latin American Adjustment: How Much Has Happened?", era proceder a uma avaliação das reformas econômicas empreendidas nos países da região. Para relatar a experiência de seus países também estiveram presentes diversos economistas latinoamericanos. Às conclusões dessa reunião é que se daria, subsequentemente, a denominação informal de "Consenso de Washington”. (BATISTA, 1994, p. 5).

A intenção do encontro era aprovar um conjunto de normativas para as operações de 'cooperação' financeira das agências às diversas entidades norte-americanas ou internacionais envolvidas com a América Latina, a fim de ratificar o ideário do neoliberalismo nesses países. Para tanto, estiverem à frente organismos financeiros como FMI, Banco Mundial e BID, e demais agências e departamentos especializados em assuntos latino-americanos (BATISTA, 1994). As propostas de cunho neoliberal faziam parte de uma taxonomia referente às reformas políticas exigidas para a América Latina que apontavam as condicionantes para empréstimos, sendo: disciplina fiscal; uma mudança nas prioridades para despesas públicas; reforma tributária; liberalização do sistema financeiro; uma taxa de câmbio competitiva; liberalização comercial; liberalização da entrada do investimento direto; privatização das empresas estatais; desregulamentação; direitos da propriedade assegurados. Essa taxonomia foi apontada pelo próprio John Williamson, economista que cunhou o termo "Consenso de Washington" para as reformas políticas na América Latina de 1980. 
O receituário dos organismos internacionais não deixou de delinear objetivos para as políticas educacionais dos países, os quais, como

fruto do processo e do padrão de desenvolvimento e dominação que se foram produzindo e engendrando relações econômico-sociais e político-ideológicas que acabaram por determinar o tipo de Estado, de poder e, particularmente, um tipo de currículo escolar como uma condensação dessas mesmas relações. (ZANARDINI, 2008, p. 45).

O currículo escolar passa a fazer parte das prescrições ideológicas do pensamento econômico dos organismos internacionais. Assim, à educação atribui-se o papel decisivo para o crescimento econômico e aliviamento da pobreza, caracterizando-se como condicionante capaz de operar nas contradições do capitalismo, como se fosse o principal meio para operar a distribuição de renda no futuro. (ZANARDINI, 2008).

Atendendo aos imperativos do mercado, a atual reforma da Educação Básica, conforme apresentada na BNCC, parece traduzir os valores essenciais para o século XXI nas dez Competências Gerais recomendadas: 1. conhecimento; 2. pensamento científico, crítico e criativo; 3. repertório cultural; 4. comunicação; 5. cultura digital; 6. trabalho e projeto de vida; 7. argumentação; 8. autoconhecimento e autocuidado; 9. empatia e cooperação; 10. responsabilidade e cidadania. Fundamentadas nas Diretrizes Curriculares Nacionais, essas competências respaldam-se em princípios éticos, estéticos e políticos, os quais, segundo as Dimensões e Desenvolvimento das Competências Gerais da BNCC, estão voltados para os "[...] conhecimentos, habilidades, atitudes e valores essenciais para a vida no século 21." (MOVIMENTO PELA BASE NACIONAL COMUM CURRICULAR, 2018, p. 1).

As Competências foram delineadas pelo Movimento pela Base Nacional Comum Curricular (IDEM), que desenvolveu um material para orientar as Dimensões e Subdimensões que as compõem, a fim de “[...] facilitar a sua inserção em currículos, práticas pedagógicas, materiais didáticos e processos de avaliação da aprendizagem." (MOVIMENTO PELA BASE NACIONAL COMUM CURRICULAR, 2018, p. 1) O material desenvolvido teve o apoio do Center for Curriculum Redesign ${ }^{3}$ (CCR, Centro de Redesenho do Currículo) visa atender às mudanças de currículos; tem como norte o estudante do século XXI e o incremento ao desenvolvimento de capital social e humano, apresentando as competências necessárias que os alunos precisam desenvolver para prosperar no mundo atual e futuro. Assim, postula quatro dimensões essenciais que devem permear os currículos em todo o mundo: Conhecimento, Habilidades, Caráter e Meta-Aprendizagem. (CENTER FOR CURRICULUM REDESIGN, 2015). 
As competências necessárias para o atual século são condições para o sucesso, por isso, o CCR carrega a concepção de um dos principais organismos internacionais, a Organização para a Cooperação e Desenvolvimento Econômico (OCDE), que tem como um dos seus principais representantes o chefe de Divisão e Coordenador do Programa Internacional de Avaliação de Alunos da OCDE, Andreas Schleicher. No Brasil, o CCR está representado pelo Instituto Península e Instituto Ayrton Senna.

Organismos internacionais como a OCDE apoiam-se na concepção de mundialização do capital e financeirização da economia, e suas perspectivas ideológicas estão bem representadas nos diagnósticos e orientações voltados para a economia política global (LIBÂNEO, 2018). Tal afirmativa pode ser observada no documento Educação em quatro dimensões, do CCR (2015), no qual se destaca o objetivo de formar indivíduos capacitados, felizes e com maior progresso econômico e equidade. A fim de atingir esse objetivo, o documento tem a reforma curricular como solução:

Temos que reformular o currículo escolar com este inevitável estado de mudança em mente e formar os estudantes para que sejam adaptáveis e versáteis. Esta é uma oportunidade. A humanidade pode refletir, adaptar e agir de maneira proativa para moldar o futuro desejado. Muitos programas educativos se concentram em melhorar como a educação é implementada. Este é um objetivo digno e importante. Mas, então, questionamos: estamos ensinando e testando as coisas certas? $O$ que deveria ser aprendido para melhor preparar os estudantes para o século XXI? (CENTER FOR CURRICULUM REDESIGN, 2015, p. 16 - grifo nosso).

O princípio educativo da organização está pautado na formação de indivíduos adaptáveis e versáteis, com vistas a preparar o futuro profissional do século XXI. O currículo escolar, de acordo com o documento mencionado, precisa acompanhar as mudanças do mundo atual e se posicionar diante do futuro incerto. Dessa forma, delimitam como deve ser a estrutura curricular:

A estrutura se concentra no conhecimento (o que os estudantes sabem e entendem), nas habilidades (como eles usam esse conhecimento), no caráter (como eles se comportam e se engajam no mundo) e no meta-aprendizado (como eles refletem sobre si mesmos e se adaptam e continuam aprendendo e crescendo para atingir seus objetivos). (CENTER FOR CURRICULUM REDESIGN, 2015, p. 16).

É com base no conhecimento e nas habilidades preconizadas nesse documento que a BNCC (BRASIL, 2017) define os conhecimentos e competências que os alunos devem desenvolver no decorrer da escolaridade, evidenciando que o documento nacional está estritamente articulado aos propósitos e recomendações do CCR, isto é, o discurso propalado pela BNCC é reflexo das intenções educativas do CCR. Sobre isso, Libâneo (2018) salienta que não se pode dizer que as finalidades determinadas por organismos internacionais definem, por si só, os rumos de uma política educacional, haja vista que cada país formula suas próprias 
políticas de acordo com suas peculiaridades econômicas e culturais. Todavia, percebe-se, no cotejamento entre os dois documentos, que as recomendações do CCR se materializam nos sistemas escolares na forma de um currículo, haja vista os 4 objetivos essenciais para a educação consignados no documento Educação em quatro dimensões, sendo o último (4. Objetivos, padrões e currículos da educação), o foco dessa organização:

O conjunto padrão comum de conhecimento, habilidades e outras competências, e como eles devem ser aprendidos, é criado para fornecer aos estudantes uma compreensão básica das disciplinas relevantes e habilidades essenciais, que, por sua vez, os ajuda a obter sucesso no mundo e a conectar as sociedades por meio do compartilhamento de ideias e referências, e uma base educacional comum. Isso é necessário para a satisfação individual e a prosperidade da sociedade. (CENTER FOR CURRICULUM REDESIGN, 2015, p. 42).

Observa-se que o objetivo do CCR é a elaboração de uma base educacional comum, em termos de conhecimentos, habilidades e competências, para que os estudantes possam obter sucesso no mundo. Coincidentemente, a BNCC no Brasil passou a ser formulada ainda no primeiro semestre de 2015 e, posteriormente, a partir da segunda versão divulgada, foi possível verificar a "[...] ênfase em métodos, procedimentos, competências e habilidades voltadas para a adaptação do indivíduo aos interesses do grande capital. Expressando a hegemonia da classe empresarial no processo de elaboração do documento" (MARSIGLIA, et. al., 2017, p. 109) Essas habilidades e competências são apresentadas como condição de desenvolvimento dos indivíduos, como se pode depreender do trecho abaixo:

É função dos padrões e currículos despertar as competências necessárias para que as
pessoas escolham conteúdo que tenha profundidade e que o analisem de maneira
inteligente. Devemos realinhar os objetivos educacionais, os padrões e os currículos
para que reflitam nosso conhecimento em constante mudança e as transformaçóes
dinâmicas que ocorrem em nosso mundo. (CENTER FOR CURRICULUM
REDESIGN, 2015, p. 43 - grifo nosso).

Os objetivos educacionais precisam, de acordo com o exposto, preparar o aluno para as constantes transformações do mundo. Para tanto, o CCR tem como pressuposto o desenvolvimento de indivíduos baseado na hierarquia das necessidades da Psicologia de Abraham Maslow: 
Figura 1 - Hierarquia das necessidades de Maslow

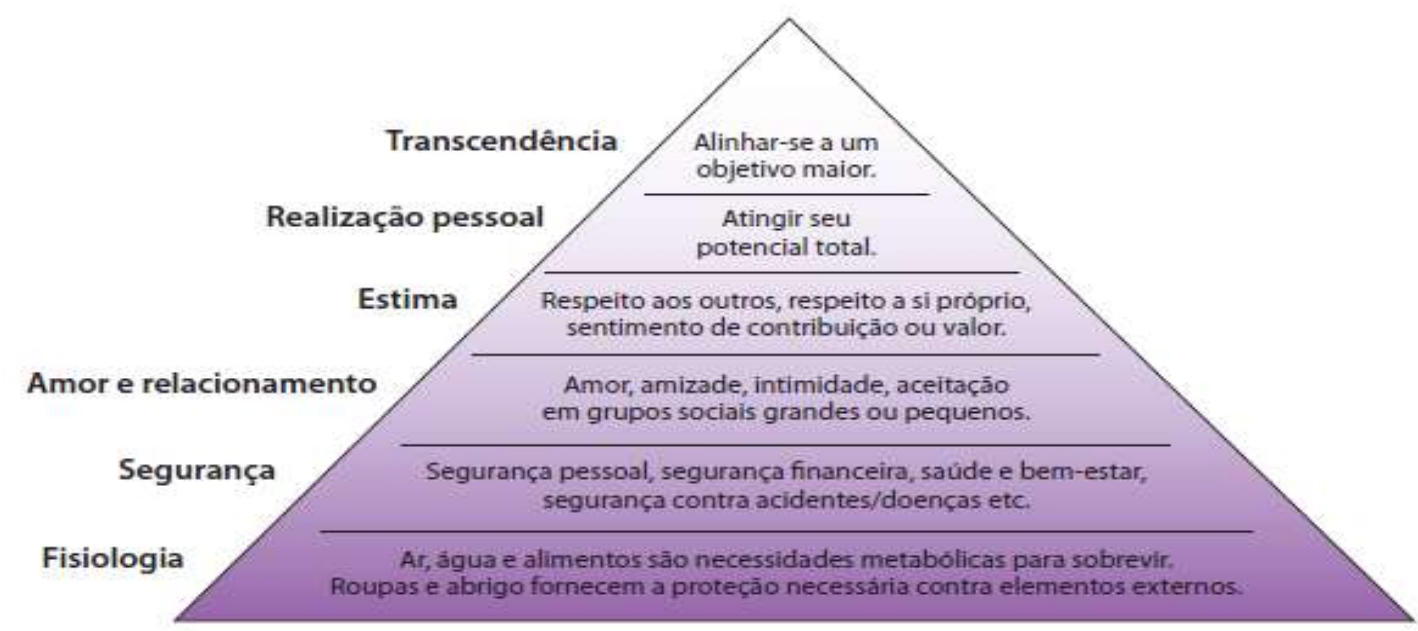

FIGURA 2.1 Hierarquia das necessidades de Maslow.

Fonte: $\mathrm{CCR}$.

Fonte: Educação em quatro dimensões - Center For Curriculum Redesign, 2015.

A teoria da hierarquia das necessidades evidencia o caráter ideológico da preparação educacional dos indivíduos, sejam eles quem forem e onde estiverem. Infere-se que se as Dimensões e Desenvolvimento das Competências Gerais da BNCC foram elaboradas com o apoio do CCR, conforme demonstra o documento elaborado pelo Movimento pela Base Nacional Comum Curricular de 2018, é possível a hipótese de que as dez competências descritas na BNCC (2017 e 2018) se fundamentam na mesma teoria - (Psicologia de Maslow) e recomendam tomá-la como referência e objetivo. A hierarquia das necessidades propostas por Maslow difunde o princípio de ordem segundo sua predominância, isto é, há uma estrutura ordenativa considerada básica para que se possa atingir a satisfação e os anseios dos indivíduos:

Isso significa que a meta mais preponderante irá monopolizar a consciência e tenderá a organizar a escolha de várias capacidades do organismo. As necessidades menos preponderantes são diminuídas, até mesmo esquecidas ou rejeitadas. No entanto, quando uma necessidade é razoavelmente satisfeita, a próxima necessidade preponderante ("maior") emerge, para, por sua vez, dominar a vida consciente e servir como centro da organização do comportamento, já que necessidades preenchidas não servem como motivadores ativos. (MASLOW, 2003, p. 5).

A Psicologia de Maslow, muito utilizada no âmbito dos negócios, defende a ideia de autorrealização do trabalho mediante a realização pré-determinada das necessidades básicas, conforme evidenciado na pirâmide da hierarquia das necessidades. Por isso, essa teoria define a concepção psicológica para a Educação em quatro dimensões - Conhecimento, Habilidades, Caráter e Meta-aprendizado do CCR, pois as "competências para sucesso" (CCR, 2015), 
resumem-se numa capacidade educativa que justifique as habilidades sociais requisitadas neste século:

[...] como o mundo está se tornando cada vez mais interconectado, nossos objetivos sociais devem se expandir para níveis mais amplos de conscientização, complexidade e escala, pois agora precisamos considerar como afetamos os outros, tanto presencial quanto virtualmente. Assim como Sócrates via a "sociedade como a alma em grande escala", na escala da humanidade global, nossos objetivos sociais mais amplos podem ser vistos como paralelos à progressão geral dos objetivos pessoais definidos na Pirâmide de Maslow. (CCR, 2015, p. 39 - grifo nosso).

A teoria da hierarquia das necessidades de Maslow é incorporada pelo CCR (2015) com o intuito de estabelecer um padrão nos objetivos educacionais para o século XXI. A padronização das habilidades essenciais, propiciará, segundo o CCR (2015), o sucesso no mundo. Isso se constitui num projeto hegemônico, ou seja, disseminar a cultura do mercado e naturalizar suas consequências como um consenso social. $\mathrm{O}$ entendimento proposto para que reformas curriculares ocorram, parte do princípio de sucesso individual e social por meio de competências e habilidades básicas necessárias do mundo econômico e tecnologicamente moderno, cujo cerne é a manutenção do status quo modernizante. (GONÇALVES, 2020).

O CCR é um órgão internacional que tem por objetivo a reformulação dos padrões educacionais do ensino básico, de forma que as justificativas propostas para a educação do século XXI permitem-nos a elucidação de conceitos que, por vezes, não estão nítidos na BNCC. O sucesso para o século XXI, proposto pelo documento do CCR "Educação em Quatro Dimensões: As competências que os estudantes precisam ter para atingir o sucesso" - 2015, significa a incorporação e desenvolvimento da meta-aprendizagem (como eles refletem sobre si mesmos e se adaptam e continuam aprendendo e crescendo para atingir seus objetivos), em suma, refere-se a capacidade de "aprender a aprender" (CCR, 2015, p. 133). Essa é, portanto, a formação com base em competências da BNCC. Isso fica evidente na definição do próprio documento:

\begin{abstract}
A sociedade contemporânea impõe um olhar inovador e inclusivo a questões centrais do processo educativo: o que aprender, para que aprender, como ensinar, como promover redes de aprendizagem colaborativa e como avaliar o aprendizado. No novo cenário mundial, comunicar-se, ser criativo, analítico-crítico, participativo, produtivo e responsável requer muito mais do que a acumulação de informações. Aprender a aprender, saber lidar com a informação cada vez mais disponível, atuar com discernimento e responsabilidade nos contextos das culturas digitais, aplicar conhecimentos para resolver problemas, ter autonomia para tomar decisões, ser proativo para identificar os dados de uma situação e buscar soluções, são competências que se contrapõem à concepção de conhecimento desinteressado e erudito entendido como fim em si mesmo. (BRASIL, 2017, p. 17 - grifo nosso).
\end{abstract}


Resiliência, aprender a aprender, curiosidade etc., são as habilidades que fundamentam o estabelecimento de um currículo para o sucesso. Por essa razão, o CCR propõe a relevância de reavaliar o que ensinamos e ênfase no aprendizado holístico:

Teremos que reavaliar com atenção a relevância do que ensinamos, organizar as disciplinas tradicionais, adicionar disciplinas modernas relevantes e colocar ênfase no aprendizado mais holístico - não apenas no conhecimento, mas também nas habilidades, caráter e meta-aprendizado. Por fim, precisaremos de coragem para inovar, saindo do conforto de um sistema existente e trabalhando em condições de incerteza rumo a um sistema melhor. (CENTER FOR CURRICULUM REDESING, 2015, p. 46 - grifo nosso).

O aprendizado holístico com base nas habilidades e o meta-aprendizado não aparecem no documento sem intencionalidade; as proposições da aprendizagem holística estão relacionadas com a Declaração de Icheon - Marco de Ação da Educação 2030, que estabelece um dos Objetivos de Desenvolvimento Sustentável (ODS-4), com o intuito de "Assegurar a educação inclusiva e equitativa de qualidade, e promover oportunidades de aprendizagem ao longo da vida para todos.” (UNESCO, 2016, p. 3). Para atingir esse objetivo, a própria Declaração destaca a urgência de uma agenda educacional que seja única, renovada, holística, ousada e ambiciosa (UNESCO, 2016). Ainda, de acordo com a Declaração:

Nossa visão é transformar vidas por meio da educação ao reconhecer seu importante
papel como principal impulsionador para o desenvolvimento e para o alcance de
outros ODS propostos. Comprometemo-nos, em caráter de urgência, com uma
agenda de educaçãa única e renovada, que seja holística, ousada e ambiciosa, que
não deixe ninguém para trás. Essa nova visão é inteiramente captada pelo ODS 4
"Assegurar a educação inclusiva e equitativa de qualidade, e promover
oportunidades de aprendizagem ao longo da vida para todos" e suas metas
correspondentes (UNESCO, 2016, Preâmbulo III - grifo nosso).

É com base numa agenda educacional única, renovada, holística, ousada e ambiciosa (UNESCO, 2016) que a BNCC se apoia na ideia de que a educação brasileira precisa voltar-se para a formação humana integral e para a construção de uma sociedade justa, democrática e inclusiva, sendo as competências uma necessidade para a composição dessa agenda educacional.

Constata-se que há uma agenda educacional por parte dos organismos internacionais que define metas e objetivos a serem atingidos, principalmente para países considerados de terceiro mundo ou emergentes, sob a justificativa de que somente as nações que a eles se adequarem estarão em condições de competir no mercado globalizado (EVANGELISTA, SHIROMA, 2006). Umas das principais ferramentas para essa adequação a essa agenda é o currículo e as prescrições de adaptabilidade, o que parece denotar apoio teórico na concepção evolucionista que regeria todos os seres vivos na natureza, com o currículo representando um mecanismo versátil para um mundo em constante mudança: 


\begin{abstract}
Ao passo que os outros animais já nascem com muitas habilidades, como caminhar, os humanos precisam de ajuda por um bom período do seu desenvolvimento. Isso ajuda a garantir que cada ser humano se ajuste ao seu ambiente e à sua cultura, pois seus cérebros se adaptam a muitas coisas que o ambiente ao seu redor exigir. $A$ versatilidade é fundamental para a sobrevivência em um mundo em constante mudança; isso também se aplica à espécie, e, portanto, também ao currículo - a base compartilhada da compreensão e competência da nossa espécie. (CENTER FOR CURRICULUM REDESIGN, 2015, p. 48 - grifo nosso).
\end{abstract}

A adaptabilidade, conforme fundamentada teoricamente pelo CCR, é o caminho versátil para a sobrevivência no mundo em constante mudança, e o currículo é entendido nessa perspectiva de que é preciso "ajustar" o ser humano ao seu ambiente e à sua cultura. No entanto, como procuramos demonstrar, falam mais alto as necessidades (e instabilidades) do mundo da produção e se toma como principais objetivos de formação do cidadão os de adaptação do homem econômico, e não do homem sociopolítico. De modo que o perfil que se espera é de um indivíduo criativo, inovador, flexível e solidário que seja capaz de lidar com as transformações tecnológicas. (EVANGELISTA; SHIROMA, 2006).

Partindo das análises dessas autoras, percebe-se que o perfil desejado do indivíduo que se pretende formar com base nas dez Competências Gerais da BNCC expressa uma busca de conhecimentos necessários para a sobrevivência no século XXI que se pauta no âmbito das necessidades econômicas. Não distanciando-se dos objetivos do CCR, a BNCC define que o conhecimento ideal é aquele que pode ser aplicado em situações que requerem decisões pertinentes a esse âmbito específico da vida social; as competências desejáveis são aquelas aplicáveis a ele, que recebem o nome de competência.

[...] na educação formal, os resultados das aprendizagens precisam se expressar e se apresentar como sendo a possibilidade de utilizar o conhecimento em situações que requerem aplicá-lo para tomar decisões pertinentes. A esse conhecimento mobilizado, operado e aplicado em situação se dá o nome de competência. (BRASIL, 2017, p. 15).

A educação com base nas competências representa a noção ideológica de um pensamento que visa moldar os indivíduos às exigências socioeconômicas. Não obstante, a BNCC segue a tendência da formação por competências propostas por reformas curriculares que vêm sendo implementadas no final do século XX e início do XXI, seguindo o enfoque das avaliações internacionais propostas pela OCDE. De acordo com a própria BNCC, 
No Brasil, essas referências legais têm orientado a maioria dos Estados e Municípios na construção de seus currículos. Essa mesma tendência de elaboração de currículos referenciados em competências é verificada em grande parte das reformas curriculares que vêm ocorrendo em diferentes países desde as décadas finais do século XX e ao longo deste início do século XXI. É esse também o enfoque adotado nas avaliações internacionais da Organização para a Cooperação e Desenvolvimento Econômico $(O C D E)$, que coordena o Programa Internacional de Avaliação de Alunos (Pisa, na sigla em inglês), e da Organização das Nações Unidas para a Educação, a Ciência e a Cultura (Unesco, na sigla em inglês), que instituiu o Laboratório Latinoamericano de Avaliação da Qualidade da Educação para a América Latina (LLECE, na sigla em espanhol). (BRASIL, 2017, p. 16 - grifo nosso).

A formação pautada em competências é parte de um conjunto de reformas curriculares em que o objetivo é o desenvolvimento das habilidades socioemocionais: saber se relacionar, trabalhar em conjunto e se adaptar às circunstâncias diversas. Nesse sentido, o currículo holístico almejado baseia-se nas aprendizagens, não só de conhecimentos, mas também de habilidades e de caráter, assim como no uso de estratégias de meta-aprendizagem:

Tradicionalmente, o principal foco de um currículo educacional é na aprendizagem dos conteúdos das áreas de conhecimento. Mas um número crescente de pesquisas de várias áreas de estudo indica a necessidade de balancear conhecimento e compreensão de conteúdo com habilidades que apliquem esse conhecimento no mundo real; qualidades do caráter que criem motivação, resiliência e inteligência socioemocional; e estratégias de metaaprendizado que ajudem os estudantes a se tornarem reflexivos, autodirecionados e especialistas. (CENTER FOR CURRICULUM REDESIGN, 2015, p. 51 - grifo nosso).

Pelas afirmações explanadas, evidencia-se que a adaptabilidade ao século XXI é a preocupação central dos reformadores de currículos. A fim de atingir esse objetivo, entendem e prescrevem a formação com base em competências como o ideal para o desenvolvimento das habilidades socioemocionais dos indivíduos. Essas são as premissas que, dado o foco nos objetivos de formação para o cidadão capaz de se adaptar ao ambiente de mudanças do século XXI, balizam teórica e ideológicamente as proposições das Competências Gerais da BNCC. Por essa razão, é preciso um olhar atento aos documentos oficiais para a educação, uma vez que as políticas educacionais contemporâneas “[...] articulam interesses, projetam políticas, produzem intervenções sociais." (EVANGELISTA, 2012, p. 52).

\section{Considerações finais}

As Competências Gerais da BNCC representam, teórica e ideologicamente, as proposições dos organismos internacionais. Essa afirmação é possível de se fazer tendo em vista que a organização principal na formulação dessas competências, o CCR, está articulado com as proposições da OCDE. Percebe-se que o discurso neoliberal das reformas educacionais, 
empreendidas ainda na década de 1990, continua presente nas propostas curriculares e são observáveis na reforma proposta pela BNCC, com base nas dez Competências Gerais, dessa forma refletindo a conservação e reprodução de uma sociedade desigual, pautada nos interesses das classes dominantes. (MARX; ENGELS, 1998).

No delinear das recomendações do CCR, as políticas educacionais devem se voltar para a formação do cidadão do século XXI, definidos como aquele capaz de se adaptar às permanentes mudanças, em especial no contexto da atividade econômica, como é o caso das propostas de dez Competências Gerais da BNCC que enfatizam as habilidades socioemocionais no desenvolvimento dos alunos.

Atualmente, é perceptível a presença de uma Agenda Globalmente Estruturada para a Educação, conforme a formulação de Dale (2004), pela qual os organismos internacionais reiteram como deve ser a educação para o século XXI, tomando como fundamento teórico o currículo holístico e renovado para a solução dos problemas sociais e econômicos. Entretanto, vários autores sustentam a tese de que não cabe à educação o condão de sustentar uma formação baseada nas exigências socioeconômicas, a exemplo de Shiroma, Moraes e Evangelista (2011). A BNCC expressa, por meio das Competências Gerais, o posicionamento teórico e ideológico de uma educação que busca na motivação, na resiliência e na inteligência socioemocional uma aprendizagem que visa manter o status quo da cultura liberal-conservadora, como formulada por Mészáros (2012).

Portanto, o discurso de equidade e qualidade empregado na atual reforma da educação e mediante a BNCC, pautado no desenvolvimento de habilidades socioemocionais, demonstra que as Competências Gerais da BNCC mantêm o funcionamento ininterrupto do modo de produção capitalista, bem como a dinâmica reprodutiva em razão dos poderosos fatores psicossociais e ideológicos de manutenção da ordem social existente (MÉSZÁROS, 2002, 2012). 


\footnotetext{
${ }^{1}$ Aprovada pelo Conselho Nacional de Educação (CNE) no dia 15 de dezembro de 2017, a base referente à Educação Infantil e Ensino Fundamental, e no dia 4 de dezembro de 2018, a BNCC do Ensino Médio.

2 A título de exemplificação, o Movimento pela Base Nacional Comum Curricular possui o apoio institucional de algumas instituições: Associação Brasileira de Avaliação Educacional (ABAVE); Centro de Estudos e Pesquisas em Educação, Cultura e Ação Comunitária (CENPEC); Comunidade Educativa (CEDAC); Conselho Nacional de Secretários de Educação (Consed); Fundação Lemann; Fundação Maria Cecilia Souto Vidigal; Fundação Roberto Marinho; Instituto Ayrton Senna; Instituto Inspirare; Instituto Natura; Instituto Unibanco; Itaú BBA; Todos Pela Educação; União Nacional dos Dirigentes Municipais de Educação (Undime).

${ }^{3} \mathrm{O}$ fundador dessa instituição (CCR) é o professor de Harvard Charles Fadel, especialista em inovações em educação
}

\section{Referências}

BATISTA, Paulo Nogueira. O Consenso de Washington: a visão neoliberal dos problemas latino-americanos. Programa Educativo Dívida Externa - PEDEX, Caderno Dívida Externa, n. 6, 2. ed., nov. 1994, p. 1 - 36.

BATISTA, Roberto Leme. A ofensiva do capital e a reestruturação produtiva no final do século XX. In: TOLEDO, Cézar de Alencar Arnaut de.; NOMA, Amélia Kimiko (Orgs.). Políticas públicas e educação na contemporaneidade. Maringá: EDUEM, 2017. p. 35-56.

BRASIL. Plano Diretor da Reforma do Aparelho do Estado. Brasília: Presidência da República, Câmara da Reforma do Estado, Ministério da Administração Federal e Reforma do Estado, 1995.

BRASIL. Parâmetros Curriculares Nacionais (PCN). Introdução. Ensino Fundamental. Brasília, MEC/SEF,1997.

BRASIL. Parecer n $n^{\circ}$ 04/98 do Conselho Nacional de Educação (CNE). Brasília: Câmara de Educação Básica do Conselho Nacional de Educação (CEB), 1998.

BRASIL. Base Nacional Comum Curricular (BNCC). Educação Infantil e Ensino Fundamental. Versão final. Brasília: MEC, 2017.

CARVALHO, Elma Júlia. Educação e diversidade cultural. In.: CARVALHO, Elma Júlia; FAUSTINO, Rosangela Célia. Educação e diversidade cultural. Maringá: Eduem, 2010, p. 17 -54 .

CENTER FOR CURRICULUM REDESIGN, Educação em quatro dimensões. Boston, 2015. Disponivel em: < https://curriculumredesign.org/our-work/four-dimensional-21st-centuryeducation-learning-competencies-future-2030/>. Acesso em: 17 ago. 2018.

DALE, R. Globalização e educação: demonstrando a existência de uma 'cultura educacional mundial comum' ou localizando uma agenda globalmente estruturada para a educação? Educação \& Sociedade, Campinas, vol. 25, n. 87, maio/ago. 2004. p. 423-460.

DEITOS, Roberto Antonio. Economia e Estado no Brasil. In: FIGUEIREDO, Ireni Marilene Zago; ZANARDINI, Isaura Monica Souza; DEITOS, Roberto Antonio. Educação, políticas sociais e Estado no Brasil. Cascavel: EDUNIOESTE; Curitiba: Fundação Araucária, 2008. p. 205-236.

HOBSBAWM, Eric J. A era do capital. 26 ed. Rio de Janeiro/São Paulo: Paz e Terra, 2017. 
EVANGELISTA, Olinda. Apontamentos para o trabalho com documentos de política educacional. In: ARAÚJO, Ronaldo Marcos de Lima; RODRIGUES, Doriedson S. (Orgs.). A pesquisa em trabalho, educação e políticas educacionais. Campinas-SP: Alínea, 2012, v. 1. p. 52-71.

EVANGELISTA, Olinda; SHIROMA, Eneida O. Educação para o alívio da pobreza: novo tópico na agenda global. Revista de Educação, PUC-Campinas, Campinas, n. 20, junho 2006. p. 43-54.

FRIGOTTO, Gaudêncio. Educação e a crise do capitalismo real. São Paulo: Cortez, 2010.

GONÇALVES, Amanda Melchiotti. Os Intelectuais Orgânicos da Base Nacional Comum Curricular (BNCC): Aspectos teóricos e ideológicos. 2020. 128 f. Dissertação (Mestrado em Educação). Universidade Estadual do Oeste do Paraná - UNIOESTE, Cascavel, 2020.

HARVEY, David. Condição pós-moderna: uma pesquisa sobre as origens da mudança cultural. Tradução de Adail Sobral; Maria Stela Gonçalves. 8. ed. São Paulo: Loyola, 1999.

LIBÂNEO, José Carlos. Políticas educacionais neoliberais e escola: uma qualidade de educação restrita e restritiva. In: LIBÂNEO, José Carlos; FREITAS, Raquel A. Marra da Madeira (Orgs). Políticas educacionais neoliberais e escola pública: uma qualidade restrita de educação escolar. Goiânia: Editora Espaço Acadêmico, 2018. p. 45-88.

MARSIGLIA, Ana Carolina Galvão; PINA, Leonardo Docena; MACHADO, Vinícius de Oliveira; LIMA, Marcelo. Germinal: Marxismo e Educação em Debate, Salvador, v. 9, n. 1, abr. 2017. p. 107-121.

MARX, Karl; ENGELS, Friedrich. A ideologia alemã. Trad. Castro e Costa, L.C. São Paulo: Martins Fontes, 1998.

MASLOW, Abraham Harold. Diário de negócios de Maslow. Tradução de Nilza Freire. Rio de Janeiro: Qualitymark, 2003.

MÉSZÁROS, István. Para além do capital: rumo a uma teoria de transição. São Paulo: Boitempo, 2002.

MÉSZÁROS, István. O poder da ideologia. Tradução Magda Lopes e Paulo Cezar Castanheira. São Paulo: Boitempo, 2012.

MOVIMENTO PELA BASE NACIONAL COMUM CURRICULAR. Dimensões $e$ Desenvolvimento das Competências Gerais da BNCC. Center for Curriculum Redesign. 2018. Disponível em <http://movimentopelabase.org.br/acontece/competencias-gerais-de-bncc/ > . Acesso em 19 abr. 2018.

NOMA, Amélia Kimiko. O neoliberalismo: doutrina, movimento e conjunto de políticas. In: TOLEDO, Cézar de Alencar Arnaut de.; NOMA, Amélia Kimiko (Orgs.). Políticas públicas e educação na contemporaneidade. Maringá: EDUEM, 2017. p. 99-124.

PAIVA, V.; WARDE, Mirian. Novo paradigma de desenvolvimento e centralização do ensino básico. Educação \& Sociedade, Campinas, v. 14, n. 44, 1993. p. 11-32. 
PERRUDE, Marileide Rodrigues da Silva. Reforma do Estado e da educação no Brasil a partir da década de 1990: novos padrões de administração pública e de gestão educacional. In: TOLEDO, Cézar de Alencar Arnaut de.; NOMA, Amélia Kimiko (Orgs.). Políticas públicas e educação na contemporaneidade. Maringá: EDUEM, 2017. p. 41-57.

SHIROMA, Eneida Oto; MORAES, Maria Célia Marcondes; EVANGELISTA, Olinda. Política educacional. 4. ed. Rio de Janeiro: Lamparina, 2011.

UNESCO, Educação 2030. Declaração de Icheon e Marco de Ação da Educação - Rumo a uma educação de qualidade, inclusiva e equitativa e à educação ao longo da vida para todos. Paris: UNESCO, 2016.

WILLIAMSON, John. Reformas políticas na América Latina na década de 80. Revista de Economia Política, São Paulo, v. 12, n. 1, 1992.

ZANARDINI, João Batista. A ideologia do desenvolvimento e da globalização e as proposições curriculares elaboradas (1961-2002). In: FIGUEIREDO, Ireni Marilene Zago; ZANARDINI, Isaura Monica Souza; DEITOS, Roberto Antonio. Educação, políticas sociais e Estado no Brasil. Cascavel: EDUNIOESTE; Curitiba: Fundação Araucária, 2008. p. 205236. 